\title{
Predictive value of early maximal exercise test and thallium scintigraphy after successful percutaneous transluminal coronary angioplasty
}

\author{
WILLIAM WIJNS, * PATRICK W SERRUYS, MAARTEN L SIMOONS, MARCEL VAN DEN \\ BRAND, PIM J DE FEIJTER, JOHAN H C REIBER, PAUL G HUGENHOLTZ
}

From the Thoraxcenter, Erasmus University and University Hospital Dijkzigt, Rotterdam, The Netherlands

SUMMARY Restenosis of the dilated vessel after percutaneous transluminal coronary angioplasty can be detected by non-invasive procedures but their ability to predict later restenosis soon after a successful angioplasty as well as recurrence of angina has not been assessed. A maximal exercise test and myocardial thallium perfusion scintigraphy were, therefore, performed in 91 asymptomatic patients a median of 5 weeks after they had undergone a technically successful angioplasty. Primary success of the procedure was confirmed by the decrease in percentage diameter stenosis from $64(12) \%$ to $30(13) \%$ as measured from the coronary angiograms and in the trans-stenotic pressure gradient (normalised for mean aortic pressure) from 0.61(0.16) to 0.17(0.09). A clinical follow up examination (8.6(4.9) months later) was carried out in all patients and a late coronary angiogram obtained in 77. The thallium perfusion scintigram showing the presence or absence of a reversible defect was highly predictive for restenosis whereas the exercise test was not. The positive predictive value of an abnormal scintigram was $82 \%$ compared with $60 \%$ for the exercise test (ST segment depression/or angina or both at peak workload). Angina or a new myocardial infarction occurred in $60 \%$ of patients with abnormal and in $21 \%$ of patients with normal scintigrams.

Restenosis of the dilated vessel after primary successful percutaneous transluminal coronary angioplasty occurs in $19-33 \%$ of cases within the first six months after the procedure. ${ }^{1-4}$ Changes in the dilated and non-dilated arteries may be detected by changes in the patient's clinical status, by non-invasive diagnostic tests, or by repeat coronary angiography. Previous work $^{25}$ has shown that an abnormal exercise test response and a myocardial perfusion deficit on thallium scintigrams was associated with an angiographically detected restenosis of the dilated vessel or with the presence of additional disease. The present study was performed to determine the value of early noninvasive testing for the prediction of restenosis and recurrence of symptoms. The patients included in this study had undergone a technically successful angiop-

Requests for reprints to Dr P W Serruys, Thoraxcenter, Erasmus University, PO Box 1738, 3000 DR Rotterdam, The Netherlands.

*Present address: Laboratory of Nuclear Medicine, UCLA School of Medicine, Los Angeles, CA 90024, USA.

Accepted for publication 11 September 1984 lasty and had remained free of angina pectoris at the time of the exercise test and thallium scintigraphy, which were performed a median of 5 weeks after the procedure. Follow up data on the recurrence of symptoms and a control coronary angiogram obtained a median of 7 months after the procedure were compared with the initial non-invasive test results.

\section{Patients and methods}

\section{STUDY POPULATION}

Of 265 consecutively attempted angioplasty procedures followed up for at least six months, 91 attempts in 87 patients ( 75 men, 12 women) were selected for this study. The inclusion criteria were $(a)$ a primary successful angioplasty, $(b)$ early maximal exercise testing combined with thallium myocardial perfusion scintigraphy, and (c) absence of anginal symptoms after the procedure until the time of non-invasive testing. A single stenosis was dilated in 89 cases and a double stenosis (left circumflex and anterior descending arteries) in two. Eight had previously undergone 
coronary artery bypass surgery. The dilated vessel was the left anterior descending artery in 61 patients, the left circumflex artery in nine, the right coronary artery in 18, and a saphenous vein bypass graft in three. Sixty seven patients had one vessel disease, 13 two vessel disease, and three three vessel disease. In the remaining eight, previous bypass surgery was performed with complete revascularisation as shown at angiography in four of them.

After angioplasty, a complete anatomical correction was obtained in 73 procedures, while additional disease not suitable for dilatation by us was still present in 18 cases. Seven of these 18 patients had unstable angina refractory to medical management. Angioplasty of the vessel thought responsible for the symptoms was attempted because the patients were not considered ideal candidates for surgery in view of associated disability or recent myocardial infarction. In the remaining 11 patients, the residual lesions not suitable for angioplasty were also not suitable for bypass surgery or reoperation.

\section{ANGIOPLASTY}

The procedure was performed according to the technique of Gruntzig et al, ${ }^{1}$ using the equipment of Schneider via a femoral route. Details regarding the procedure used in our laboratory have been previously described.$^{67}$ The procedure was considered to be successful when the residual stenosis was $<50 \%$ in diameter with a good runoff and filling of the distal vessel at angiography. In the 87 cases with satisfactory recordings, the residual pressure gradient (normalised for the mean aortic pressure) was $<0.2$ in 57 cases and $<0.4$ in 28.8

All patients received nifedipine $10 \mathrm{mg}$ every two hours for the first 12 hours after the procedure and were maintained on salicylic acid $500 \mathrm{mg}$ a day and nifedipine $10 \mathrm{mg}$ 3-6 times a day until repeat angiography was performed. Beta blocking agents were withdrawn unless hypertension was present.

\section{EXERCISE TEST AND MYOCARDIAL THALLIUM SCINTIGRAPHY}

The non-invasive exercise studies were performed $5 \cdot 2(2.5)$ weeks (mean (SD)) after the angioplasty. Before testing, a careful history was obtained and only patients free of typical angina were included. The subjects underwent a maximal or symptom limited exercise test on the bicycle ergometer with stepwise increments of $20 \mathrm{~W}$ every minute. Intravenous dipyridamole ${ }^{9}$ was used as an alternative for the exercise test in four patients who were unable to cycle. The three orthogonal leads XYZ of the Frank lead system were monitored, processed, and analysed as previously described.10 Horizontal ST depression $\geqslant 0.1 \mathrm{mV}$ or typical angina during exercise were consi- dered to be an abnormal (or positive) exercise test response. One minute before peak exercise, thallium $50 \mathrm{MBq}(1.5 \mathrm{mCi})$ was injected intravenously and imaging started five minutes later in the anterior and left anterior oblique $45^{\circ}$ and $65^{\circ}$ views. Static planar images (500 kcounts full field) were obtained after exercise and four hours later. The late images were corrected for acquisition time differences with respect to the early images. After interpolative background correction $^{11}$ and automated left ventricular contour detection, ${ }^{12}$ circumferential profiles were computed and compared with the normal range defined by the upper and lower tenth percentile at each point of the profile from 15 normal subjects. These methods used for data collection and processing have been described before. ${ }^{12}$ The analogue images and the circumferential profiles were prospectively analysed on a consensus basis by three experienced observers without knowledge of the angiographic data. The segmental thallium uptake was scored both in the postexercise and late images on a four point scale, from normal (3) to absent $(0)$. The scores of all segments were summed for each patient and the total difference between late and early postexercise scores was taken as a measure of the amount of redistribution. An increase in thallium uptake score of two points or more between postexercise and late images was taken as the cutoff between normal and abnormal scintigrams. Using this analysis, the previously reported sensitivity and specificity for the diagnosis of coronary artery disease were $80 \%$ and $88 \%$ respectively. ${ }^{12}$

\section{ANGIOGRAPHIC FOLLOW UP AND QUANTITATIVE CORONARY ANGIOGRAPHY}

A repeat coronary angiogram was requested in all 91 patients six months after the angioplasty and actually performed in 77 . The interval from the procedure was $7.4(2.5)$ months in the patients who remained asymptomatic and 5.5(2.7) months in the patients who had recurring symptoms. Angiograms were obtained in multiple views (including hemiaxial views for the left coronary artery) and were interpreted by the angiographers without knowledge of the non-invasive test results. Restenosis was defined as an increase in the diameter stenosis of the dilated lesion to $>50 \%$. In addition, quantitative analysis of the dilated stenosis was obtained in the same angiographic projection before and after angioplasty and at follow up by means of our computer based coronary angiographic analysis system..$^{73}$

\section{CLINICAL FOLLOW UP}

The patients were followed up in the outpatient clinic until the occurrence of typical angina pectoris or a new myocardial infarction, or both, repeat angioplasty, or coronary artery bypass grafting. Clinical 
information was obtained in all 91 patients and the follow up duration was 8.6(4.9) months (mean (SD). No patient died during this period.

\section{ANALYSIS OF RESULTS}

Results are presented as mean (standard deviation). Paired or unpaired $t$ tests were used whenever appropriate. The predictive value of a given test or of a combination of tests was calculated as the percentage of patients with an event among those who had that given test result. The influence of the extent of the thallium reversible defect on its predictive value was assessed by the Armitage test. ${ }^{14}$

\section{Results}

Table 1 gives details of the angioplasty procedure and of the exercise test for patients with restenosis of the dilated lesion $(n=23)$, with long term successful angioplasty but additional disease $(n=17)$, and with long term successful angioplasty and complete anatomical correction $(n=37)$, and patients without angiographic follow up $(n=14)$. Before angioplasty the mean percentage diameter stenosis was slightly less in those patients with primary successful dilatation and additional disease $(\mathrm{p}<0.05)$, but no significant difference between groups was observed after the procedure. At follow up, on average no further change was observed except, by definition, for those patients with restenosis (Fig. 1). There was no significant difference between groups in the pressure gradient across the stenosis either before or after the angioplasty. Similarly, the time of exercise testing after the procedure and the maximal workload and heart rate achieved were comparable in all groups.

Ninety six per cent of the patients who exercised reached $80 \%$ of their predicted maximal workload. An abnormal exercise test was found in 30 patients: 18 had ST segment depression, 10 angina at peak workload, and two both. Exercise induced ischaemia as assessed by the thallium redistribution was observed in 41 patients. During follow up, angina recurred in 34 patients and two had a new myocardial infarction in the territory of the dilated vessel (an inferior infarction due to right coronary artery occlusion two years after successful angioplasty of the left anterior descending coronary artery was also observed). Nine patients had a repeat angioplasty and three underwent coronary artery bypass surgery. Among these, one patient with a successful angioplasty at five months had unstable angina pectoris seven months later owing to progression of coronary artery disease in other vessels (Table 2).

\section{PREDICTIVE VALUE OF TESTS}

Figure 2a shows the predictive value of the noninvasive tests in the 77 patients with follow up angiograms. An abnormal thallium scan was associated with a high probability of restenosis or with the presence of additional disease; this probability was not influenced by the exercise test result $(81 \%$ of restenosis when both tests were abnormal vs $83 \%$ when tests were discordant). Conversely, a normal thallium scan was associated with a low probability of restenosis or additional disease or both. This probability was also not influenced by the exercise test result

Table 1 Angiographic findings before and after percutaneous transluminal coronary angioplasty (PTCA) and details of exercise testing according to four patient groups

\begin{tabular}{|c|c|c|c|c|}
\hline & $\begin{array}{l}\text { Restenosis } \\
(n=23)\end{array}$ & $\begin{array}{l}\text { Additional disease } \\
(n=17)\end{array}$ & $\begin{array}{l}\text { Long term success } \\
(n=37)\end{array}$ & $\begin{array}{l}\text { No control angiography } \\
(n=14)\end{array}$ \\
\hline \multicolumn{5}{|c|}{ Angiographic findings } \\
\hline $\begin{array}{l}\text { Dilated vessel: } \\
\text { LAD } \\
\text { LCX } \\
\text { RCA } \\
\text { Bypass }\end{array}$ & $\begin{array}{l}18 \\
1 \\
3 \\
1\end{array}$ & $\begin{array}{l}10 \\
4 \\
3 \\
-\end{array}$ & $\begin{array}{l}24 \\
3 \\
10 \\
-\end{array}$ & $\begin{array}{l}9 \\
1 \\
2 \\
2\end{array}$ \\
\hline$\%$ (Mean, SD) diameter stenosis: & & & & \\
\hline $\begin{array}{l}\text { Before PTCA } \\
\text { After PTCA } \\
\text { At follow up }\end{array}$ & $\begin{array}{l}67(14) \\
32(13) \\
63(11)\end{array}$ & $\begin{array}{l}58(12) \\
25(14) \\
30(12)\end{array}$ & $\begin{array}{l}65(11) \\
31(12) \\
32(12)\end{array}$ & $\begin{array}{l}68(12) \\
30(10) \\
-\end{array}$ \\
\hline $\begin{array}{l}\text { Mean (SD) pressure gradient* } \\
\text { Before PTCA } \\
\text { After PTCA }\end{array}$ & $\begin{array}{l}0.66(0.15)(n=22) \\
0.18(0.11)(n=23)\end{array}$ & $\begin{array}{l}0.58(0 \cdot 10)(\mathrm{n}=16) \\
0.18(0.9)(\mathrm{n}=15) \\
\text { Exercise test }\end{array}$ & $\begin{array}{l}0.60(0.14)(n=36) \\
0.16(0.8)(n=8)\end{array}$ & $\begin{array}{l}0.57(0.23)(n=14) \\
0.16(0.11)(n=13)\end{array}$ \\
\hline Mean (SD) No of weeks after PTCA & $5 \cdot 3(2 \cdot 6)(3-12)$ & $5 \cdot 2(2 \cdot 1)(2-8)$ & $4.9(1.8)(2-8)$ & $5.6(2 \cdot 4)(3-12)$ \\
\hline $\begin{array}{l}\text { Mean (SD) maximal workload (\% of } \\
\text { predicted) } \\
\text { Mean (SD) maximal heart rate (beats/min) }\end{array}$ & $\begin{array}{l}93 \cdot 2(15 \cdot 3) \\
146(28)\end{array}$ & $\begin{array}{l}98 \cdot 2(13 \cdot 7) \\
147(27)\end{array}$ & $\begin{array}{l}90(16 \cdot 5) \\
151(22)\end{array}$ & $\begin{array}{l}99 \cdot 3(14 \cdot 3) \\
146(23)\end{array}$ \\
\hline
\end{tabular}

Translesional pressure gradient is normalised for the mean aortic pressure.

$\star$ LAD, left anterior descending, LCX, left circumflex, RCA, right coronary artery;

$\mathrm{n}$, number of available measurements. 


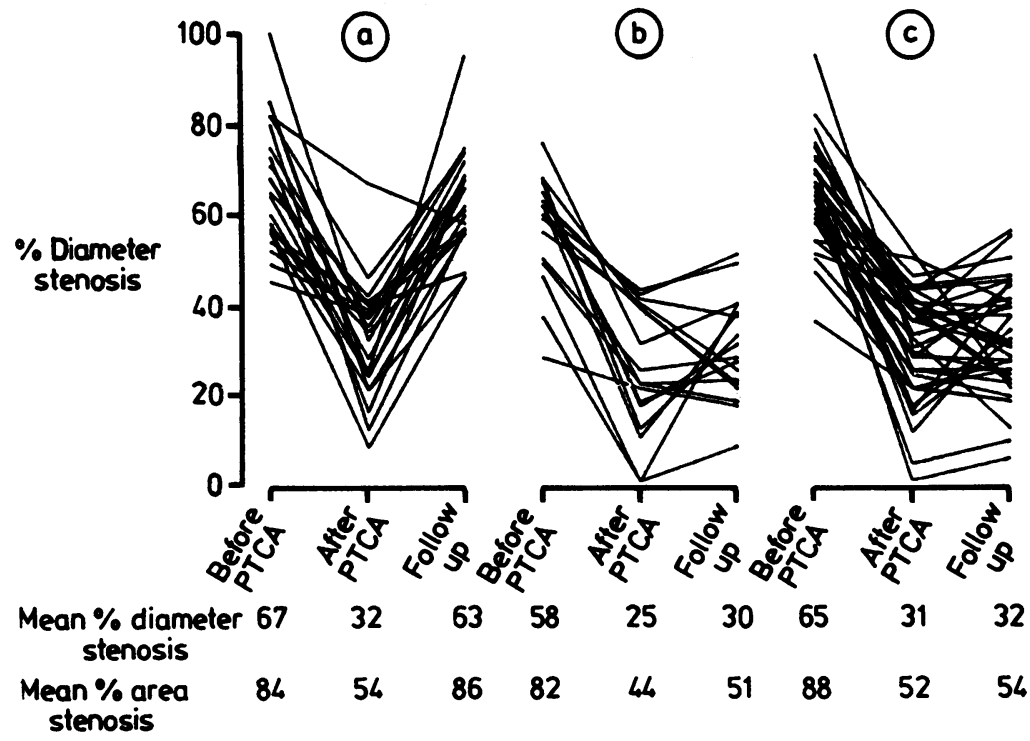

Fig. 1 Percentage diameter of the dilated stenosis for patients with (a) restenosis $(n=23)$, (b) additional disease $(n=17)$, and (c) complete correction $(n=37)$ as shown by quantitative angiography before and after angioplasty and at late follow up.

(29\% of restenosis when both tests were normal vs $22 \%$ when tests were discordant). Figure $2 b$ shows similar findings in the subgroup of patients with complete anatomical correction after the angioplasty. The predictive value of an abnormal thallium scan was $74 \%$ whereas the probability of restenosis in patients with a normal thallium scan was $16 \%$. Again, the exercise test result had no predictive value.

Figure 3 shows the value of the non-invasive tests results for the prediction of recurrence of angina or occurrence of a new myocardial infarction or both in all 91 patients. The probability of a later coronary event was $65 \%$ when both tests were abnormal and decreased to $52 \%$ when only the thallium scan was abnormal. In the presence of a normal thallium scan, the probability was low (about $20 \%$ ) regardless of the result of the exercise test. The positive and negative predictive values were respectively $60 \%$ and $78 \%$ for thallium scintigraphy and $53 \%$ and $67 \%$ for the exercise test.

Table 3 shows the influence of the severity of ischaemia on the predictive value of the thallium scintigram. As far as the angiographic endpoint was concerned, the percentage of patients with restenosis or additional disease or both increased from 24 when no ischaemia was present to 75 when a slight degree of redistribution was observed $(p<0.001)$, which was even below the abnormality threshold used in this

Table 2 Exercise test results and recurrence of symptoms during follow up in four patient groups

\begin{tabular}{|c|c|c|c|c|}
\hline & $\begin{array}{l}\text { Restenosis } \\
(n=23)\end{array}$ & $\begin{array}{l}\text { Additional disease } \\
(n=17)\end{array}$ & $\begin{array}{l}\text { Long term angiographic } \\
\text { success }(n=37)\end{array}$ & $\begin{array}{l}\text { No repeat angiography } \\
(n=14)\end{array}$ \\
\hline \multicolumn{5}{|l|}{ Abnormal exercise test: } \\
\hline Angina & 1 & 3 & 6 & - \\
\hline $\begin{array}{l}\text { ST depression } \\
\text { Both }\end{array}$ & 7 & 3 & 4 & 4 \\
\hline $\begin{array}{l}\text { Both } \\
\text { Abnormal scintigram }\end{array}$ & $\overline{17}$ & 11 & $\overline{6}$ & 7 \\
\hline \multicolumn{5}{|l|}{ Symptoms: } \\
\hline Recurrent angina & 16 & 8 & 6 & 4 \\
\hline New myocardial infarction & - & 2 & - & - \\
\hline \multicolumn{5}{|l|}{ Treatment: } \\
\hline Repeat angioplasty & 7 & 2 & - & - \\
\hline Coronary artery bypass graft & 1 & 1 & 1 & - \\
\hline
\end{tabular}




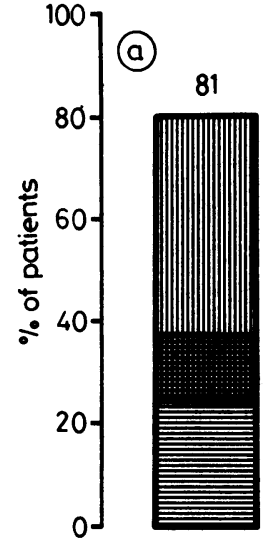

Thallium scan ( + )

Exercise test (+)

(n)

16

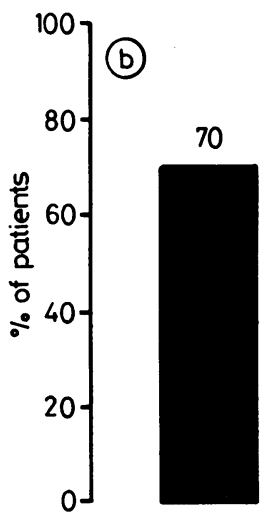

Thallium scan (t)

Exercise test (t)

(n)

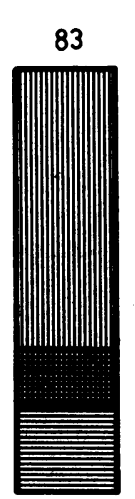

(4)

(-)

18

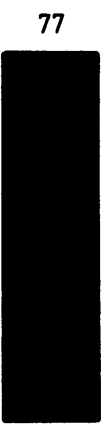

(+)

(-)

13

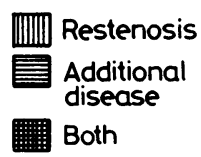

22

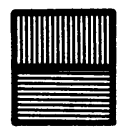

(-)

(t)

9

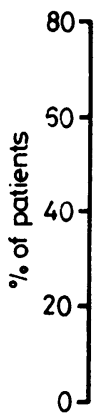

Thallium scan Exercise test

(n)

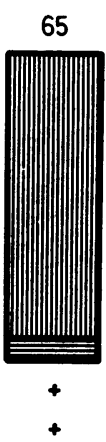

20

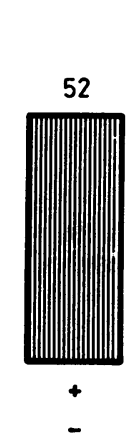

21
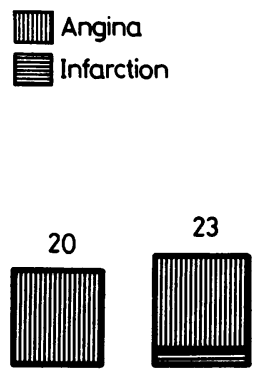

40
(-)

(-) 34

Fig. 3 Predictive value for recurrence of angina or myocardial infarction or both of the non-invasive tests. $n$, number of patients; $(+)$, abnormal test; $(-)$, normal test.

raphy after a successful angioplasty has a high predictive value for restenosis and recurrence of angina during the follow up period. Since restenosis after the procedure is known to occur mainly during the first 4-6 months after the procedure, ${ }^{2-4}$ the repeat coronary angiography was planned at six months unless angina recurred earlier. Furthermore, the duration of the clinical follow up (mean 8.6 months) was deliberately short since symptoms recurring after than period are more likely to be related to the progression of coronary artery disease rather than to restenosis of the initially dilated vessel.

Changes in the severity of the stenosis were assessed visually by the angiographers and objectively characterised in a single projection by a computer based analysis system. The mean percentage diameter stenosis for the entire group before angioplasty was $63 \%$. This value is at least $10 \%$ lower than that which is commonly reported when eyeball readings of the angiograms are relied on. ${ }^{1516}$ Visual interpretation of diameter reductions is known to systematically overestimate the severity of the stenosis. ${ }^{17}$ Moreover, lumen reductions of $90 \%$ are rarely suitable for angio-

study. Further increase in the size or in the severity of the reversible thallium defect was not associated with an increased probability of significant restenosis at angiography. On the contrary, the percentage of patients who had a coronary event during the follow up period increased stepwise as the ischaemia became more severe $(p=0.001)$.

\section{Discussion}

The present study shows that the early assessment of myocardial perfusion by exercise thallium-201 scintig-

Table 3 Effect of the severity of ischaemia on the predictive value of thallium scintigraphy

\begin{tabular}{lllll}
\hline & \multicolumn{4}{c}{ Redistribution score } \\
\cline { 2 - 6 } & 0 & 1 & 2 & $>3$ \\
\hline $\begin{array}{l}\text { \% Restenosis or additional disease } \\
\text { or both }\end{array}$ & 24 & $75 \dagger$ & 71 & 84 \\
$\begin{array}{l}\text { Recurrence of angina or } \\
\text { infarction or both }\end{array}$ & 22 & $29 \dagger$ & $50 \dagger$ & $67 \dagger$ \\
\hline
\end{tabular}

$\star$ Difference in thallium uptake score from postexercise to late image; $t p<0.001$ ( $p$ represents the significance of each probability increment according to the severity of ischaemia). 
plasty since such lesions, with an obstructed diameter of as little as $0.35 \mathrm{~mm}$, are unlikely to be.crossed even by a low profile deflated balloon catheter which has a mean diameter of $0.8 \mathrm{~mm}$. As shown experimentally, ${ }^{18}$ angioplasty induces non-axisymetric changes of the atherosclerotic lesions so that they can no longer be assessed from a single angiographic projection. Accordingly, the use of orthogonal or multiple projections has been recommended. ${ }^{19}$ This was not a major limitation in this study since after angioplasty intrapatient changes were the main interest.

Previous studies using non-invasive tests to evaluate the results of angioplasty have focused on the reversibility of the ischaemic changes after a successful procedure and on their induction at the time of recurrence. ${ }^{252021}$ The ability of the non-invasive tests to predict restenosis and recurrence of angina has not been evaluated. The study from the Montreal group, however, reports observations similar to our findings': among six asymptomatic patients who had persistently abnormal thallium scintigrams one month after angioplasty restenosis was present at six months in two (out of five) who had a control angiogram.

In the present study, the high predictive value of the perfusion scintigram contrasts with the poor predictive value of the exercise test, at least for the prediction of restenosis. This might be related to a lower sensitivity of the exercise test for the detection of moderate coronary narrowing compared with thallium scintigraphy. The combination of a normal exercise test with a reversible thallium perfusion abnormality could be an early indicator of the presence of a non-critical stenosis, still insufficient to induce ST segment depression during exercise. ${ }^{22}{ }^{23}$ Indeed, $60 \%$ of the patients with an initially abnormal scintigram became symptomatic during the follow up period. Thus the most likely explanation for our findings is that restenosis had already occurred to some extent at the time of non-invasive testing in the majority of patients in whom it was detected later. Pathological studies of the underlying mechanism of restenosis after dilatation support this hypothesis. Fibrocellular proliferation as a reparative response to coronary wall laceration has been found in necropsy studies ${ }^{24}$ and may represent the pathological substrate of early restenosis. By analogy with aortic dissection, exposure of vascular smooth muscle cells to blood may trigger an exuberant tissue reaction leading to the obliteration of the false channel and eventually of the functional lumen. Data from experimental angioplasty in pigs suggest that balloon dilatation is a potent stimulus to early platelet deposition and subsequent intimal hyperplasia.25 In this model, the reparative process was seen by two weeks after the procedure. That may have allowed the early detection of restenosis in our patients.
Another possible explanation for our findings may be that the abnormal scintigrams occurred predominantly in patients in whom the dilatation was incomplete. This seems unlikely to us since only successful cases were included and the decrease in the severity of the stenosis and in the trans-stenotic pressure gradients was comparable in patients with restenosis and sustained angiographic success. Because of a selection bias, restenosis of the dilated artery occurred in $30 \%$ of the patients who had a control angiogram, while angina pectoris recurred in $40 \%$ of all patients. These results do not represent the true incidence of restenosis at our institution since the availability of a thallium scintigram was a requirement for inclusion in this study. The high incidence of recurrent angina must also be related to the inclusion of patients with disease in additional vessels in whom dilatation, although successful, did not result in complete anatomical correction. Hence, an obligatory long term relief of symptoms could not be expected. Angina recurred in $61 \%$ ( 11 out of 18 ) of these patients.

The clinical implications of these findings for the routine management of patients undergoing angioplasty remain to be elucidated. Certainly an abnormal stress thallium scintigram early after the procedure in an asymptomatic patient is an indication for close clinical monitoring in view of the high chance of the recurrence of symptoms. Currently, we consider that decisions to perform a control angiogram, followed by a redilatation when restenosis is found, should primarily be based on the severity of the anginal symptoms rather than on the results of the testing procedure by itself. This is analogous to the issue of bypass surgery for documented coronary artery disease in asymptomatic patients, particularly now that no benefit of surgical intervention over pharmacological treatment was found in mildly symptomatic or asymptomatic patients. ${ }^{26} \mathrm{As}$ long as the outcome of prophylactic angioplasty has not been studied, the procedural complications and incomplete success rates would militate against carrying out angioplasty when diagnostic testing shows restenosis in the absence of symptoms.

We thank $J$ Tijssen and $M$ Patijn for statistical analysis of the data and $P$ van Eldik for quantitative analysis of the angiograms.

\section{References}

1 Grüntzig AR, Senning A, Siegenthaler WE. Nonoperative dilatation of coronary-artery stenosis: percutaneous transluminal coronary angioplasty. $N$ Engl f Med 1979; 301: 61-8.

2 Scholl JM, Chaitman BR, David PR, et al. Exercise electrocardiography and myocardial scintigraphy in the serial evaluation of the results of percutaneous transluminal 
coronary angioplasty. Circulation 1982; 66: 380-90.

3 Kaltenbach M, Scherer D, Kober G. Longterm results of coronary angioplasty [Abstract]. Circulation 1983; 68 (suppl III): 95.

4 Holmes D, Vlietstra R, Smith H, et al. Restenosis following percutaneous transluminal coronary angioplasty (PTCA): a report from the NHLBI PTCA registry [Abstract]. Circulation 1983; 68 (suppl III):95.

5 Hirzel HO, Nuesch K, Gruentzig AR, Luetolf UM. Short- and long-term changes in myocardial perfusion after percutaneous transluminal coronary angioplasty assessed by Thallium-201 exercise scintigraphy. Circulation 1981; 63: 1001-7.

6 Serruys PW, van den Brand M, Brower RW, Hugenholtz PG. Regional cardioplegia and cardioprotection during transluminal angioplasty, which role for nifedipine? Eur Heart f 1983; 4: [suppl C] 115-21.

7 Serruys PW, Wijns W, van den Brand M, et al. Is transluminal coronary angioplasty mandatory after successful thrombolysis? Br Heart $\mathcal{F}$ 1983; 50: 257-65.

8 O'Neill WW, Vogel RA, Aueron FM, et al. The physiologic significance of translesional gradients obtained during arteriographically successful coronary angioplasty [Abstract]. Circulation 1983; 68 (suppl III): 163.

9 Albro PC, Gould KL, Westcott RJ, Hamilton GW, Ritchie JL, Williams DL. Noninvasive assessment of coronary artery stenoses by myocardial imaging during pharmacologic coronary vasodilation. III Clinical trial. Am $\mathcal{F}$ Cardiol 1978; 42: 751-60.

10 Simoons ML, Hugenholtz PG. Estimation of the probability of exercise-induced ischemia by quantitative ECG analysis. Circulation 1977; 56: 552-9.

11 Watson DD, Beller GA, Berger BC, Teates CD. Notes on the quantitation of sequential thallium-201 images. Software 1979; 6: 4-10.

12 Reiber JHC, Lie SP, Simoons ML, Wijns W, Gerbrands JJ. Computer quantification of location, extent and type of thallium-201 myocardial perfusion abnormalities. In: International symposium on medical imaging and image interpretation. New York: Institute of Electrical and Electronics Engineers, 1982; Cat No 82 CH 1804-4: 123-128.

13 Serruys PW, Booman F, Troost GJ, et al. Computerized quantitative coronary angiography applied to the PTCA procedure; advantages and limitations. In: Kaltenbach M, Gruentzig A, Rentrop K, Bussmann WD, eds. Transluminal coronary angioplasty and intracoronary thrombolysis. New York: Springer Verlag, 1982: 110.

14 Armitage P. Tests for linear trends in proportions and frequencies. Biometrics 1955; 11: 375-86.

15 Cowley MJ, Vetrovec GW, Wolfgang TC. Efficacy of percutaneous transluminal coronary angioplasty: technique, patient selection, salutary results, limitations and complications. Am Heart f 1981; 101: 272-80.

16 Kent KM, Bentivoglio LG, Block PC, et al. Percutaneous transluminal coronary angioplasty: report from the registry of the National Heart, Lung and Blood Institute. Am $\mathcal{F}$ Cardiol 1982; 49: 2011-20.

17 Gerbrands JJ, Reiber JHC, Booman F. Computer processing and classification of coronary occlusions. In: Gelsema ES, Kanal LN, eds. Pattern recognition in practice. New York: North Holland, 1980: 223.

18 Block PC, Baughman KL, Pasternak RC, Fallon JT. Transluminal angioplasty: correlation of morphologic and angiographic findings in an experimental model. Circulation 1980; 61: 778-85.

19 Meier B, Gruentzig AR, Goebel N, Pyle R, von Gosslar W, Schlumpf $M$. Assessment of stenoses in coronary angioplasty. Inter-and intraobserver variability. Int $\mathcal{f}$ Cardiol 1983; 3: 159-69.

20 Kent KM, Bonow RD, Rosing DR, et al. Improved myocardial function during exercise after successful percutaneous transluminal coronary angioplasty. $N$ Engl f Med 1982; 306: 441-5.

21 Kanemoto N, Hör G, Kober G, et al. Noninvasive assessment of left ventricular performance following transluminal coronary angioplasty. Int $\mathcal{F}$ Cardiol 1983; 3: 281-92.

22 Pohost GM, Alpert NM, Ingwall JS, Strauss HW. Thallium redistribution: mechanisms and clinical utility. Semin Nucl Med 1980; 10: 70-93.

23 Serruys PW, Reiber JHC, Simoons ML, van den Brand $M$. Pressure gradient and cross sectional area stenosis in patients with and without exertional angina: what is a 'critical stenosis'? [Abstract]. Am $\mathcal{F}$ Cardiol 1982; 49: 926.

24 Essed CE, van den Brand M, Becker AE. Transluminal coronary angioplasty and early restenosis: fibrocellular occlusion after wall laceration. $B r$ Heart $\mathcal{f}$ 1983; 49: 393-6.

25 Steele PM, Chesebro JH, Lamb HB, Stanson AW, Badimon L, Fuster V. Natural history of balloon angioplasty in pigs: wall injury, platelet-thrombus deposition and intimal hyperplasia [Abstract]. Circulation 1983; 68 (suppl III): III-264.

26 Braunwald E. Effects of coronary-artery bypass grafting on survival: implications of the randomized coronaryartery surgery study. $N$ Engl $\mathcal{F}$ Med 1983; 309: 1181-4. 